\title{
Evaluation of disease activity in a population of Russian JIA patients
}

\author{
OM Kostareva*, IP Nikishina, SF Erdes, SO Salugina \\ From 18th Pediatric Rheumatology European Society (PReS) Congress \\ Bruges, Belgium. 14-18 September 2011
}

\section{Background}

The estimation of activity of disease in JIA patients is difficult, and the instruments of an estimation borrowed from adult rheumatology aren`t much useful for JIA patients.

\section{Objectives}

To assess the correlation between disease activity scores, using the Juvenile Arthritis Disease Activity Score (JADAS), Disease activity score 28 (DAS 28) and Physician`s assessment of disease activity by VAS (PhGloVAS) on a cohort of JIA patients including in the crosssectional epidemiological study in Russian Federation (RUS).

\section{Methods}

During 3-moths cross-sectional study in 30 centers of RUS the data of 1099 consecutive patients were collected. The following key determinants of disease activity were examined: numbers of tender, swollen joints; number of active joint and joints with patient assessment of pain and global health scores (VAS); ESR; DAS 28; JADAS-71, PhGloVAS. Relationship between studied variables was investigated using of a nonparametric method of Spearman's correlation analysis.

\section{Results}

There were 1099 patients with a mean age of $10.51 \pm$ 4.54 years and the female/male ratio was 1.6. The distributions of JIA patients according to ILAR cacategories were as follows: systemic 122 (11.1\%), oligoarticular 483 (43.94\%), RF positive polyarthritis 81 (7.37\%), RF negative polyarthritis $350(31.84 \%)$, enthesitis-related 45 $(4.09 \%)$, psoriatic $18(1.63 \%)$. The median disease

Scientific research Institute of Rheumatology of RAMS, Moscow, Russian Federation duration was $4.5 \pm 3.85$ years. The mean value of JADAS71 score was $13.04 \pm 10.46$ ( $95 \%$ CI 0.618$)$, the mean value of DAS-28 score was $3.13 \pm 1.46(95 \% \mathrm{CI} 0.08)$ and mean value PhGloVAS scales was $37 \pm 24(95 \%$ CI 1.0$)$. The JADAS-71 correlated with PhGloVAS ( $r=0.8$, $\mathrm{p}<0.05)$ and DAS $28(\mathrm{r}=0.79, \mathrm{p}<0.05)$. Patients have been distributed on groups according to degree of activity depending on index DAS 28 . In group with remission (DAS $28<2.6)$ were 445 patients $(40.49 \%)$, with low activity (DAS 28 2.6-3.2) were 208 patients (18.93\%), with moderate activity (DAS 28 3.2-5.1) were 343 patients $(31.21 \%)$, with high activity (DAS $28>5.1$ ) were 103 patients $(9.37 \%)$. In each group the correlation between JADAS, DAS 28 was defined. The strongest relationship was determined in patients with high activity $(r=0.79-0.68, p<0.02)$, and the poor relationship was in group with low activity $(\mathrm{r}=0.79-0.21, \mathrm{p}<0.0001)$. In this group $(n=208)$ percent of the tendered and swelled joints which are not considered in an index DAS 28 , were $51,1 \%$ and $40,87 \%$ respectively. The greatest percent of not considered involved joints was in group of patients with a sJIA (68.9\% tender joints and $71.23 \%$ swelled). Hip, talocrural, and temporal-mandibular joints often enough are involved at this diagnosis $(18.03 \%$, $44.26 \%, 2.46 \%$ respectively in our analysis) and define functional insufficiency. As a whole, on all cohort of patients the poor relationship between DAS and JADAS is at patients with enthesitis-related arthritis $((\mathrm{r}=0.79$ $0.63, \mathrm{p}<0.036)$.

\section{Conclusion}

JADAS and DAS 28 demonstrated strong correlation at a high degree of activity and poor correlation at a low degree of activity. Joints of the bottom extremities and others aren't considered in index DAS 28, but make appreciable percent from total number of the involved 
joints . DAS 28 it is applicable for an estimation of activity of disease not at all diagnoses JIA

Published: 14 September 2011

doi:10.1186/1546-0096-9-S1-P209

Cite this article as: Kostareva et al:. Evaluation of disease activity in a population of Russian JIA patients. Pediatric Rheumatology 2011 9(Suppl 1):P209.

Submit your next manuscript to BioMed Central and take full advantage of:

- Convenient online submission

- Thorough peer review

- No space constraints or color figure charges

- Immediate publication on acceptance

- Inclusion in PubMed, CAS, Scopus and Google Scholar

- Research which is freely available for redistribution

Submit your manuscript at www.biomedcentral.com/submit
C Biomed Central 